\title{
TESTS ON AN INTERIOR REINFORCED CONCRETE BEAM-COLUMN JOINT
}

\author{
R. Park* , L. Gaerty**, and E.C. Stevenson***
}

\section{SYNOPSIS:}

Cyclic loading tests simulating the effects of a severe earthquake were conducted on an interior reinforced concrete beam-column joint. The unit had been designed according to the requirements of the draft (1980) SANZ concrete design code except that the horizontal shear reinforcement in the joint core was deliberately made only $78 \%$ of that required by the draft SANZ code. The joint core hoops commenced to yield in the first loading run up to the beam flexural strength and with subsequent loading runs degradation of stiffness and strength occurred due to damage concentrating in the joint core. It was evident that the draft SANZ code is not conservative in its approach to the design of shear reinforcement for interior reinforced concrete beam-column joints.

\section{INTRODUCTION:}

The draft (1980) SANZ concrete design codel contains recommendations for the detailing of reinforced concrete beamcolumn joints. The commentary of the draft code states that "The basic requirements of a beam-column joint are that it must perform satisfactorily under service loads, that its strength should not normally govern the strength of the structure, and that its behaviour should not impede the development of the full strength of the adjoining members".

The Commentary also acknowledges that seismic loading is a more severe loading case than static gravity loading "because strength degradation of the concrete in the joint may occur under repeated loading, and a large amount of joint reinforcement is therefore required."

The recommendations of the draft SANZ codel $^{l}$ lead to substantial amounts of joint core shear reinforcement, normally in the form of horizontal hoops and vertical column bars between the corner bars passing through the joint. The shear forces in the joint core are assumed to be carried by a mechanism consisting of a concrete diagonal compression strut and a mechanism consisting of truss action from a concrete diagonal compression field and the shear reinforcement. However when plastic hinges form in the beams adjacent to the column faces the shear carried by the diagonal compression strut mechanism is assumed to be zero unless the column axial compression is significant, or horizontal prestressing steel is present in the central one-third of the beam depth. This is because under reversed loading a full depth flexural crack forms and the participation of the concrete diagonal compression strut in the transfer of forces from the beam through the joint core can be greatly reduced. The draft code recommendations are based mainly on analyses and tests of beam-column joints conducted in New Zealand.

* Professor of Civil Engineering, Uni. of Cant.

** Snr. Lecturer in Civil Engineering.

*** Former graduate student, Dept of Civil

Engineering, Uni. of Cant.

BULLETIN OF THE NEW ZEALAND NATIONAL SOCIETY FOR EARTHQUAKE ENGINEERING, VOL. 14, NO. 2, JUNE 1981
Difficulties have been experienced in placing the large amount of shear reinforcement required by the draft SANZ code in the joint cores of some frames, particularly when the beam and column sections are small and contain large percentages of longitudinal reinforcement. Another aspect of joint core design is that the adverse bond conditions for the longitudinal bars passing through the need to be kept reasonably small, as is recommended in the draft SANZ code.

For the beam-column test unit described in this paper the quantity of horizontal joint core hoop steel provided was deliberately made only $78 \%$ of that required to satisfy the draft SANZ code. The test was conducted to evaluate the performance of such an underdesigned joint core during simulated seismic load reversals.

\section{DETAILS OF TEST UNIT:}

The beam-column test unit had the overall dimensions shown in Fig. 1 . cross sections may be taken as being representative of about $\frac{1}{2}$ to $\frac{3}{4}$ size members of a typical multistorey building frame. Both the beam and the column were continuous through the joint. The test unit can be regarded as being that part of the joint region of a plane frame between the mid-span of the beams and the mid-height of the columns. The column sections were designed to be stronger than the beam sections and during severe seismic type loading the plastic hinging occurred in the beams adjacent to the column faces. The unit was loaded as shown in Fig. 2 by axial loads $P$ at the ends of the columns and by vertical loads $V$ at the ends of the beams, while the ends of the columns were held in a vertical line by the reactive horizontal loads $\mathrm{H}$. By reversing the directions of the loads $V$ on the beams the effects of earthquake loading was simulated. The load reversals were applied slowly. The joint core mean that the bar diameters 

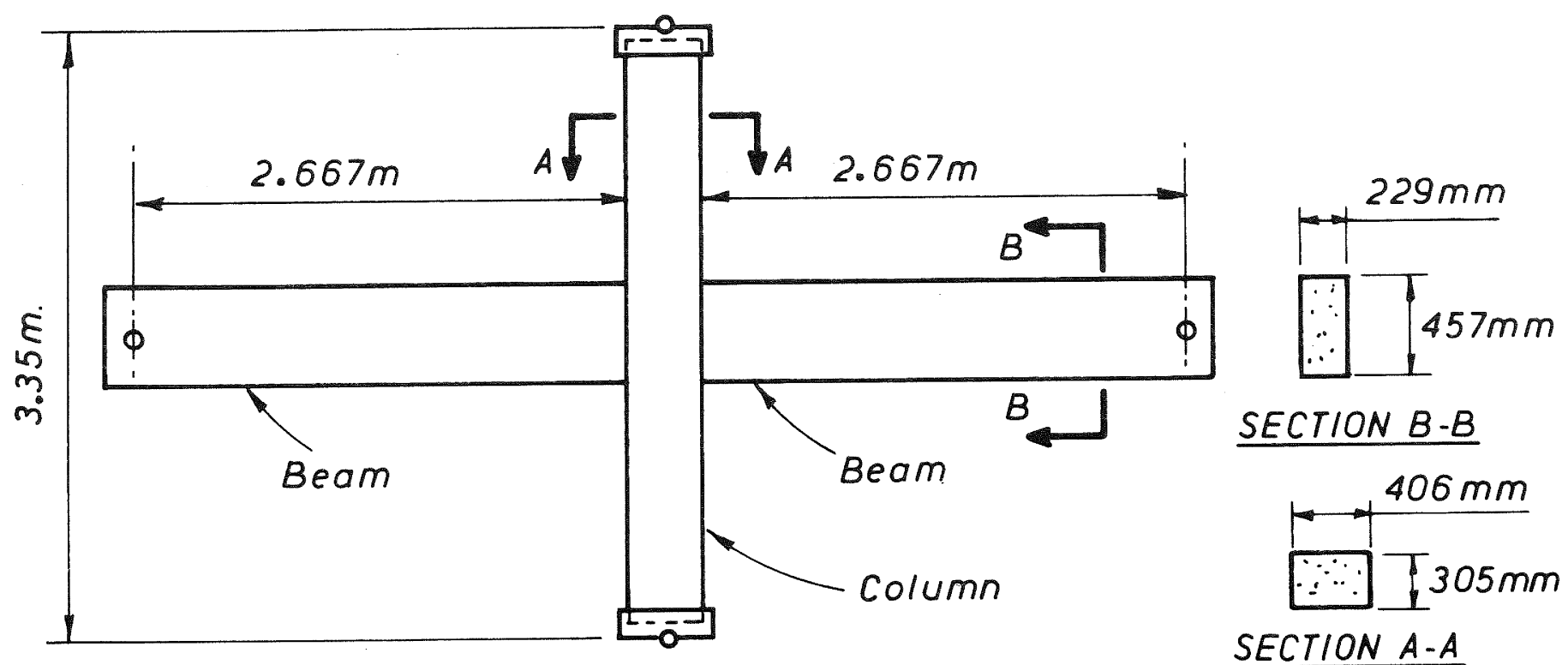

SECTION B-B

$406 \mathrm{~mm}$
$\because \because] 305 \mathrm{~mm}$

SECTION A-A

Fig. 1 Dimensions of Beam-Column Test Unit

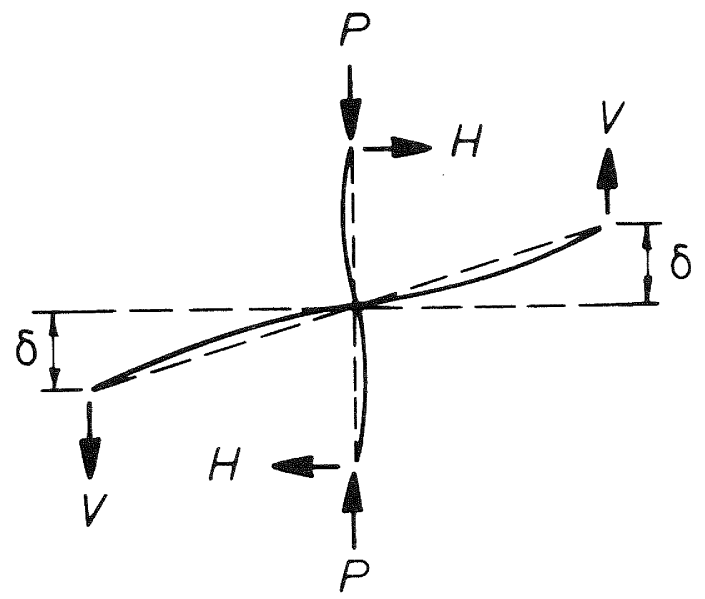

Fig. 2 Loading of Unit 
The concrete was from ordinary Portland cement and graded aggregate with a maximum aggregate size of $20 \mathrm{~mm}$ and a slump of $75 \mathrm{~mm}$. At the time of testing the unit (age 41 days) the concrete compressive cylinder strength was $34 \mathrm{MPa}$ and the split cylinder tensile strength was $3.3 \mathrm{MPa}$. The test unit was cast in the horizontal plane and damp cured for a week after casting.

The steel reinforcement had the yield and ultimate strengths shown in Table 1. The stress-strain curve for the Grade 275 D-16 reinforcement, used for longitudinal beam reinforcement, is shown in Fig. 3.

The steel reinforcement details for the unit are shown in Fig. 4.

The beams were designed to satisfy the draft SANZ codel. The beams contained eight $16 \mathrm{~mm}$ diameter Grade 275 deformed bars in the top and in the bottom $\left(\rho=\rho^{\prime}=0.0175\right)$ and the ratio of column depth to beam longitudinal bar diameter was $403 / 16=25.4$. The closed stirrups were from $10 \mathrm{~mm}$ diameter Grade 275 plain round bars and were placed at $89 \mathrm{~mm}$ centres within the potential plastic hinge regions of the beams adjacent to the columns over a length of twice the beam depth, and at $178 \mathrm{~mm}$ centres elsewhere. The stirrups were capable of carrying all of the beam shear force by truss action. The ratio of stirrup spacing to beam longitudinal bar diameter was $89 / 16=5.6$ in the potential plastic hinge regions.

The columns contained six $20 \mathrm{~mm}$ diameter Grade 380 deformed bars, with four corner bars and two intermediate bars at mid-depth in the plane of the loading. The column ties outside the joint core were formed from $10 \mathrm{~mm}$ diameter Grade 275 plain round bar. Each tie set consisted of a rectangular tie with a supplementary cross tie at the intermediate bars.

The tie sets were placed at $178 \mathrm{~mm}$ centres. In the end regions of the columns the quantity of transverse steel provided was only about $60 \%$ of the one-half of full confinement required by the draft SANZ code in potential plastic hinge regions of columns which are designed with sufficient strength to provide a high degree of protection against plastic hinging. It was felt that this smaller quantity of transverse steel was warranted since plastic hinging could not occur in the columns of the test specimens.

The beam-column joint core contained five rectangular hoops from $16 \mathrm{~mm}$ diameter Grade 275 plain round bar with supplementary cross ties of the same bar size and type passed between the intermediate column bars. The hoops were distributed as evenly as possible between the outermost layers of the top and bottom beam reinforcement at an average spacing of $86 \mathrm{~mm}$ between centres. Only the hoops acted as horizontal shear reinforcement since the supplementary cross ties were at right angles to the direction of shear transfer. The intermediate column bars acted both as vertical shear reinforcement in the joint core and as flexural reinforcement in the column. The hoops provided only $78 \%$ of the quantity of horizontal shear reinforcement required by the draft SANZ code, but the requirements for vertical shear reinforcement were satisfied.

\section{THEORETICAL STRENGTHS OF UNIT:}

In all strength calculations the strength reduction factor $\phi$ was taken as unity and the actual material strengths were used.

\section{Strengths of Members -}

The flexural strengths of the beam and column sections were calculated assuming an extreme fibre concrete compressive strain of 0.003 , a rectangular compressive stress block as given by the draft SANz code, and using the actual stress-strain curve of the longitudinal steel. The calculation was conducted assuming perfect bond between steel and concrete, and by satisfying the requirements of equilibrium of internal forces and strain compatibility. The neutral axis depth and the internal forces found for the beam sections are given in Table 2 using the notation shown in Fig. 5.

The theoretical flexural strength was found to be $203 \mathrm{kNm}$ for the beam, and $240 \mathrm{kNm}$ for the column with an axial load of $996 \mathrm{kN}$ present.

At the theoretical flexural strength of the beam the maximum applied shear force in the beam was $40 \%$ of the theoretical beam shear strength, and the maximum applied shear force in the columns was $57 \%$ of the theoretical column shear strength.

\section{Strength of Joint Core -}

The theoretical maximum applied horizontal shear force in the joint core was found to be $966 \mathrm{kN}$ when calculated from the equation

$\mathrm{V}_{\mathrm{jh}}=\mathrm{T}_{1}+\mathrm{T}_{2}+\mathrm{C}+\mathrm{C}_{4}-\mathrm{T}_{3}-\mathrm{V}_{\mathrm{col}}$

where the notation is shown in Figs. 4 and 5. The beam internal forces used were those found for the theoretical flexural strength calculation listed in Table 2 and $\mathrm{V}_{\mathrm{col}}$ was the theoretical column shear force when the beam reaches flexural strength.

Table 3 shows a comparison of the theoretical horizontal shear strengths calculated using the procedures of the draft SANZ codel, Appendix A of ACI $318-77^{2}$ the SEAOC code 3 , and the recommendations of ACI-ASCE Committee 3524 . All the procedures sum the horizontal shear force "carried by the concrete" and "carried by the hoops". The differences in Table 3 arise from the different empirical expressions and assumptions made by the various procedures. For the shear carried by the hoops, the draft SANZ code assumes a corner to corner diagonal tension crack, whereas the other approaches assume a $45^{\circ}$ diagonal tension crack. Hence when the 


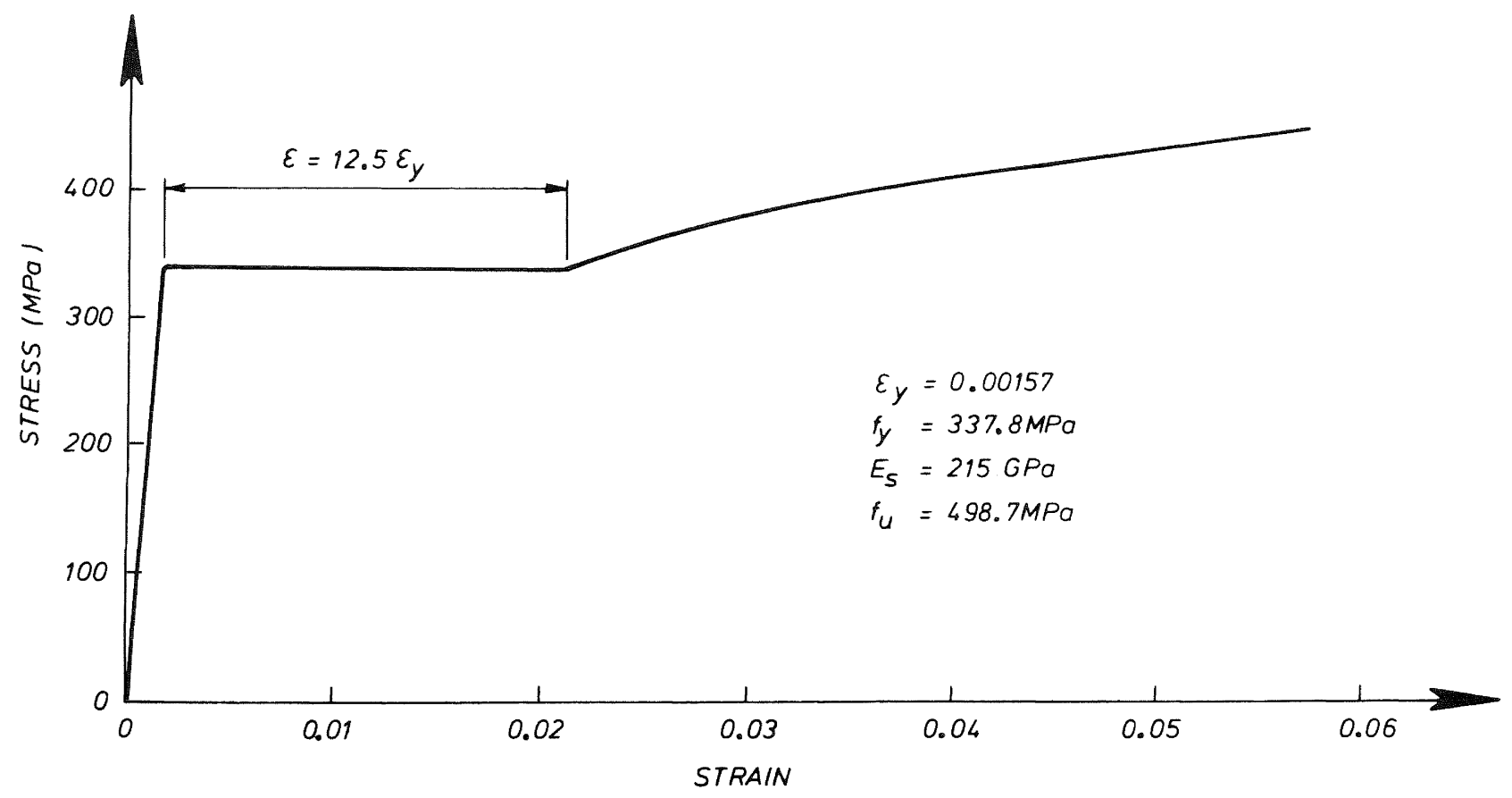

Fig. 3 Stress-Strain Relation for Grade 275 D-16 Beam Flexural Reinforcement

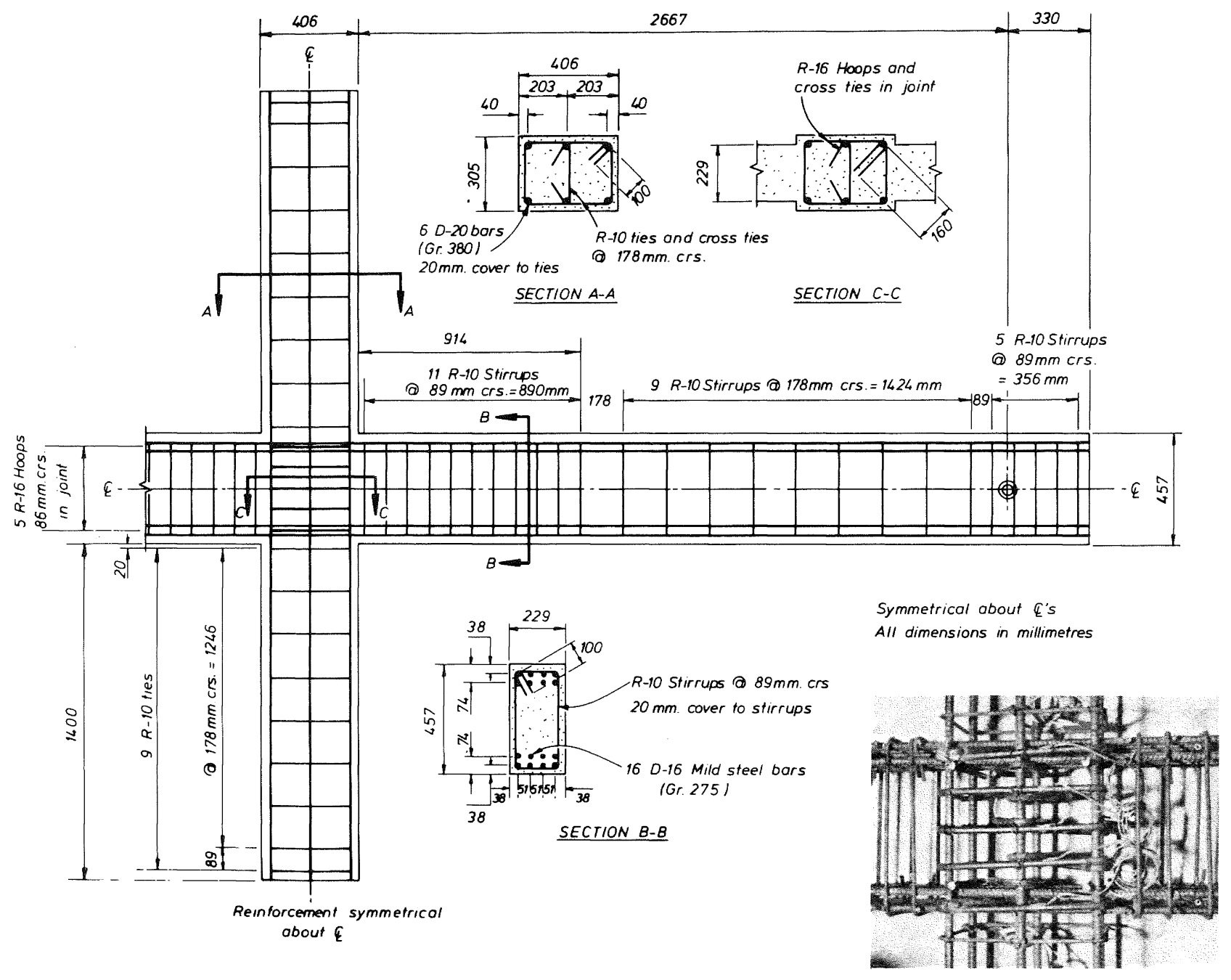

Fig. 4 Reinforcement Details of Unit 


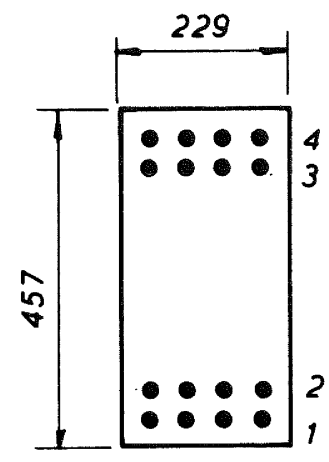

SECTION
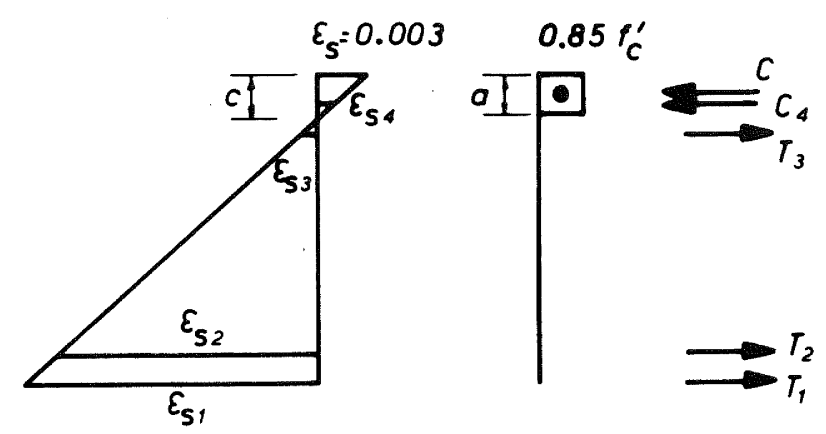

STRAINS

RESULTANT
EOUIVALENT

CONCRETE

STRESS

FORCES

Fig. 5 Beam Section at the Flexural Strength

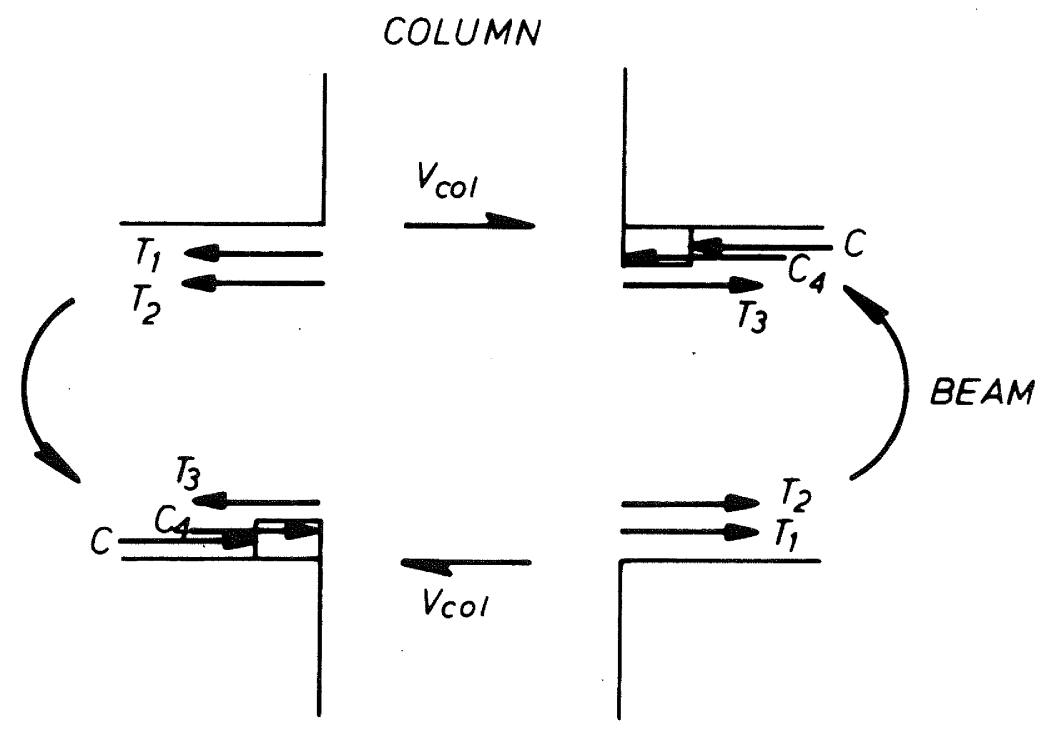

Fig. 6 Beam Internal Forces and Column Shear Acting to Cause Horizontal Shear on Joint Core. 


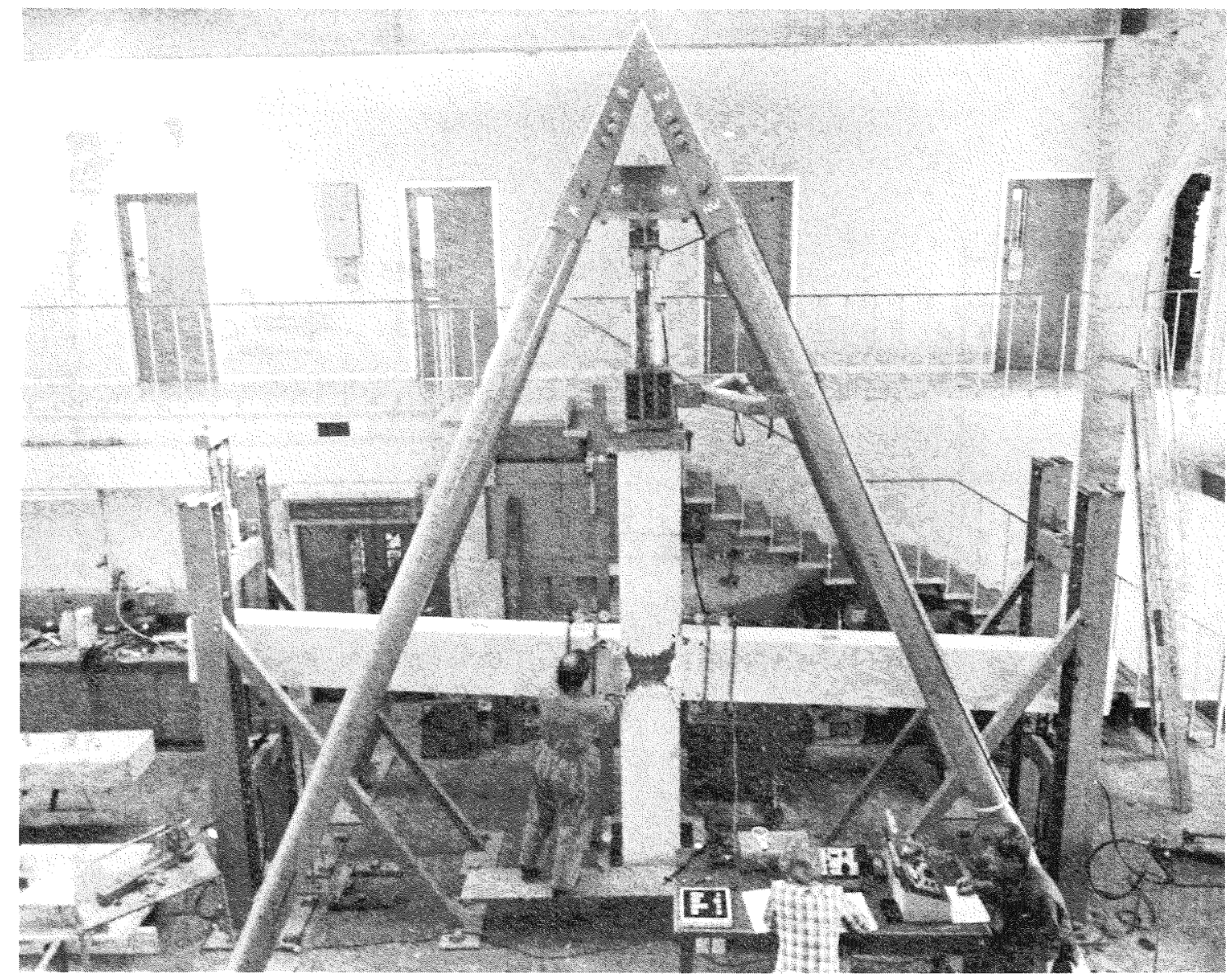

Fig. 7 Unit Under Test

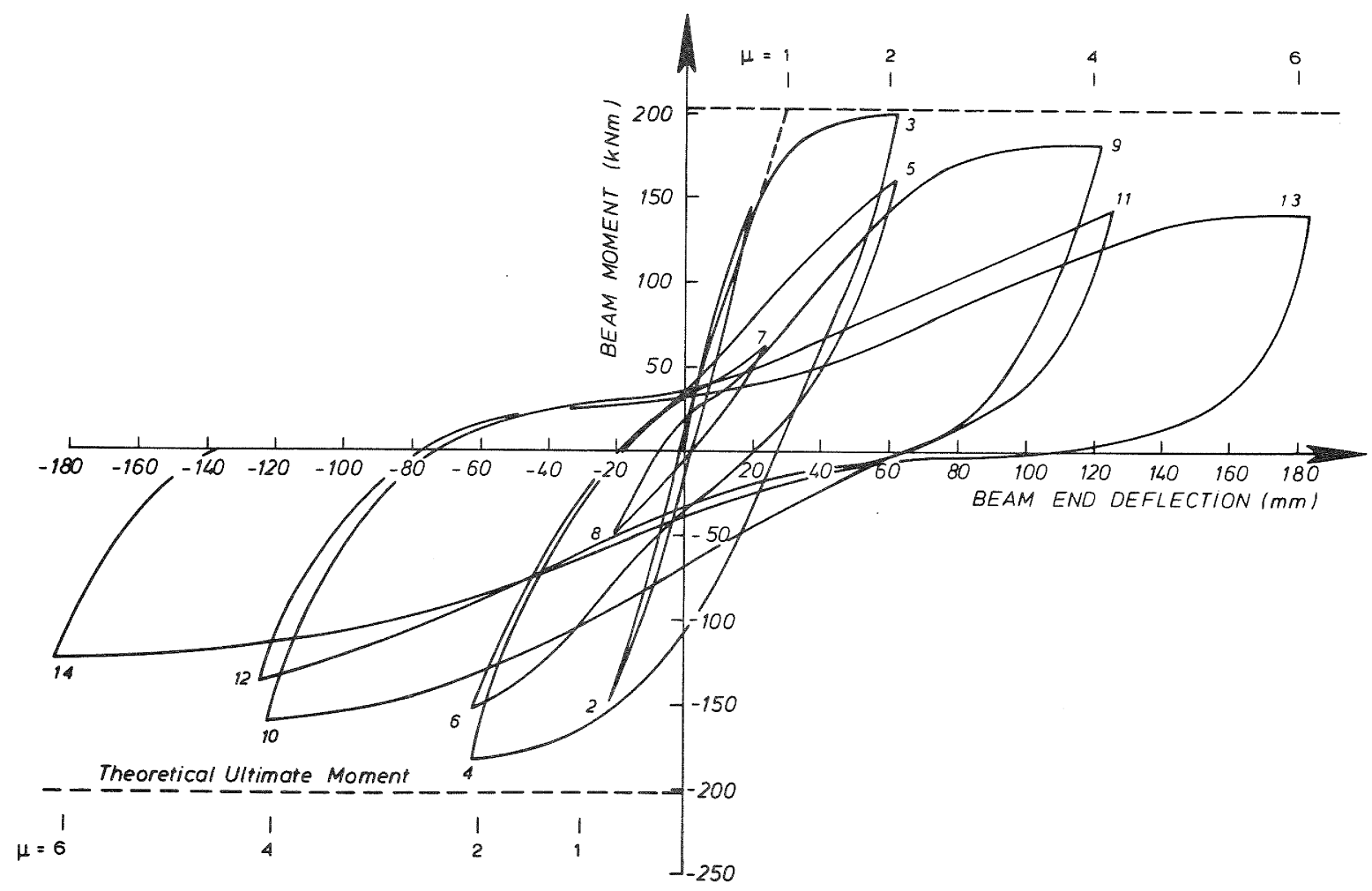

Fig. 8 Measured Beam Moment at Column Face Versus Left Beam End Deflection. 
beam depth exceeds the column depth the shear carried by the hoops is greater when calculated by the draft SANZ code than when calculated by the other procedures. For the shear carried by the concrete, the draft SANZ code and ACI 318-77 use the gross area of the core section, whereas the SEAOC code and ACI-ASCE Committee 352 use the section within the core width; SEAOC and ACI 318-77 use the same shear stress expression, but the draft SANZ code and ACI-ASCE Committee 352 use different expressions. There is not a great difference between the values for the shear carried by the concrete listed in Table 3 but this happens to be the result for the particular axial load level of the test, namely $P=0.24 f_{c}^{\prime} g^{\circ}$ The shear carried by the concrete in the draft SANZ code is zero when $\mathrm{P} / \mathrm{f}_{\mathrm{C}}^{\prime A} \mathrm{~A}<0.1$ and increases with higher axial load levels; in ACI $318-77$ it has the value for beams at $P / F_{C}^{\prime}{ }^{A} g=0$ and increases with higher axial load levels; in the SEAOC code it is zero when $P / f_{C} A_{g} \leqslant 0.12$ and is a little less than the ACI value at higher loads; and in the ACI-ASCE Committee 352 recommendations it remains at constant value for all axial load levels. Thus there can be wide differences between the values calculated for the shear carried by the concrete by the various procedures at various axial load levels.

Note also that a major difference between the draft SANZ code and the other procedures is that the draft SANz code requires the presence of vertical shear reinforcement in the joint core, normally in the form of intermediate column bars, whereas the other procedures ignore the question of vertical shear reinforcement and do not require any.

It is also worth commenting that the draft SANZ code recommends the use of a strength reduction factor of $\phi=1$, whereas ACI 318-77, SEAOC and ACI-ASCE Committee 352 recommend the use of $\phi=0.85$. Hence in many situations in design the draft SANZ code requirements for horizontal shear reinforcement will not be as demanding as the requirements of the other procedures.

The background to the draft SANZ code provisions are in its commentary, and an explanation of the mechanisms of shear transfer across joint cores by diagonal compression strut action ("shear carried by the concrete") and truss action of the shear reinforcement and a concrete diagonal compression field ("shear carried by the hoops") are given elsewhere 5,6 .

Table 4 lists the areas of horizontal shear reinforcement (from the hoops) and vertical shear reinforcement (from the intermediate column bars) actually present in the joint core and compares them with those required by the draft SANZ code. The design horizontal shear force for this code calculation was taken as $V_{j h}=966 \mathrm{kN}$, as given by Eq. 1, and the design vertical shear force was taken as $\mathrm{V}_{j h} \mathrm{~h}_{\mathrm{b}} / \mathrm{h} \mathrm{c}=1087 \mathrm{kN}$, where $h_{b}$ is the depth of the beam and $h_{c}$ is the depth of the column.

\section{TEST PROCEDURE:}

The beam-column unit was subjected to several slow load reversals simulating very severe earthquake loading. The first loading cycle was to about $\frac{3}{4}$ of the yield load, and this was followed by a series of deflection controlled inelastic cycles comprising two full cycles to each of the displacement ductility factors of 2 and 4 and then one cycle to a displacement ductility factor of 6 . The axial column load was held at $996 \mathrm{kN}$ throughout the test. The "first yield" displacement was found using the cracked elastic stiffness, as found from the stiffness at the yield load, and extrapolating linearly up to the theoretical ultimate flexural load.

Longitudinal strains in the beam steel were measured using a Demec strain gauge with a $102 \mathrm{~mm}$ gauge length. The Demec points were attached to the ends of steel studs which had been welded to the longitudinal steel and which projected sideways through holes in the cover concrete. Strains on the steel hoops in the joint core were measured using electrical resistance strain gauges which were positioned on the steel so that any bending of the hoop bar due to the tendency of the concrete to bulge outwards would not alter the strain reading. Curvatures of the beam in the potential hinge regions were measured using dial gauges attached to steel holding frames which in turn were attached to horizontal steel bars which passed through the concrete core just inside the longitudinal steel. The shear distortion of the joint core was found from Demec strain gauge readings made in the direction of the joint core diagonals. The Demec points for the shear distortion readings were attached to the ends of horizontal steel bars which passed through the joint core just inside the intersecting beam and column longitudinal bars.

The unit under test is shown in Fig. 7. The column ends had been grouted into steel caps and the column loads were applied through steel pins which allowed free rotation during the testing. The beam loads were also applied through steel pins which allowed free rotation at the load points.

\section{TEST OBSERVATIONS:}

The overall deflection behaviour measured for the test unit, the visual appearance of the unit during testing, and the strains measured on the steel hoops and on the longitudinal beam reinforcement at the critical sections are shown in Figs, 8 to 11 .

Fig. 8 shows the vertical deflection at the end of left beam plotted against the beam moment at the column face. The plot for the right beam was almost identical to that shown. The numbers in the curves correspond to the peaks of the loading runs. In loading runs 1 and 2, which 
Table 1 : Steel Properties

\begin{tabular}{|l|c|c|c|}
\hline Bar Size & Grade & $\begin{array}{c}\text { Yield Strength, } \\
\text { MPa }\end{array}$ & $\begin{array}{c}\text { Ultimate } \\
\text { Strength, MPa }\end{array}$ \\
\hline R-10 & 275 & 283 & 432 \\
R-16 & 275 & 305 & 462 \\
D-16 & 275 & 338 & 499 \\
D-20 & 380 & 412 & 665 \\
\hline
\end{tabular}

Table 2 : Beam Internal Forces

\begin{tabular}{|c|c|c|c|c|c|c|}
\hline $\begin{array}{c}\mathrm{C} \\
\mathrm{mm}\end{array}$ & $\begin{array}{c}\mathrm{a} \\
\mathrm{mm}\end{array}$ & $\begin{array}{l}\mathrm{T}_{1} \\
\mathrm{kN}\end{array}$ & $\begin{array}{l}\mathrm{T}_{2} \\
\mathrm{kN}\end{array}$ & $\begin{array}{l}\mathrm{T}_{3} \\
\mathrm{kN}\end{array}$ & $\begin{array}{c}\mathrm{C}_{4} \\
\mathrm{kN}\end{array}$ & $\begin{array}{l}\mathrm{C} \\
\mathrm{kN}\end{array}$ \\
\hline 67.6 & 55.3 & 272 & 272 & 49 & 227 & 366 \\
\hline
\end{tabular}

Table 3 : Horizontal Shear Strength of Joint Core

\begin{tabular}{|c|c|c|c|c|c|}
\hline \multicolumn{5}{|c|}{ Theoretical Horizontal Shear Strength, $\mathrm{kN}$} & \multirow{2}{*}{$\begin{array}{l}\text { Theoretical Maximum } \\
\text { Applied Horizontal } \\
\text { Shear Force, kN }\end{array}$} \\
\hline $\begin{array}{l}\text { Shear } \\
\text { Mechanism }\end{array}$ & $\begin{array}{l}\text { Draft } \\
\text { SANZ } \\
\text { Code }\end{array}$ & $\begin{array}{l}\text { ACI } \\
318-77\end{array}$ & SEAOC & $\begin{array}{l}\text { ACI-ASCE } \\
\text { Committee } 352\end{array}$ & \\
\hline $\begin{array}{l}\text { Shear } \\
\text { carried } \\
\text { by concrete }\end{array}$ & 178 & 172 & 158 & 165 & \\
\hline $\begin{array}{l}\text { Shear } \\
\text { carried } \\
\text { by hoops }\end{array}$ & 613 & 522 & 522 & 522 & \\
\hline $\begin{array}{l}\text { Total } \\
\text { shear } \\
\text { strength }\end{array}$ & 791 & 694 & 680 & 687 & 966 \\
\hline
\end{tabular}

Note: Actual material strengths used and $\phi=1$ assumed.

Table 4: Horizontal and Vertical Shear Reinforcement in Joint Core and required by Draft SANZ Code

\begin{tabular}{|c|c|c|c|}
\hline \multicolumn{2}{|c|}{$\begin{array}{c}\text { Area of Horizontal Shear Reinforcement } \\
\mathrm{mm}^{2}\end{array}$} & \multicolumn{2}{|c|}{$\begin{array}{c}\text { Area of Vertical Shear Reinforcement } \\
\mathrm{mm}^{2}\end{array}$} \\
\hline Existing in Joint Core & $\begin{array}{c}\text { Draft SANz } \\
\text { Requirement }\end{array}$ & Existing in Joint Core & $\begin{array}{l}\text { Draft SANz } \\
\text { Requirement }\end{array}$ \\
\hline 2,010 & 2,584 & 628 & 432 \\
\hline
\end{tabular}


were in the elastic range, fine corner to corner cracks developed in the joint core and flexural cracks initiated in the beams. The maximum moment capacity of the beams was reached in loading run 3 , accompanied by yielding of longitudinal steel and very slight cracking of the compressed concrete at the column faces. The maximum crack widths in loading run 3 were $0.4 \mathrm{~mm}$ for the joint core diagonal tension cracks, and $3 \mathrm{~mm}$ for the beam flexural cracks at the column faces. Measurements of the shear distortion of the joint core at the end of loading run 3 showed that about $39 \%$ of the beam end deflection at that stage was due to joint core shear distortion. In loading run 4 the diagonal tension cracks in the joint core opened to a maximum crack width of $1.6 \mathrm{~mm}$, and the flexural cracking in the beams was generally less apparent than in loading run 3 , although full depth flexural cracks existed in the beams at the column faces. Subsequent inelastic loading cycles resulted in more extensive diagonal tension cracking in the joint core and eventually to spalling of the cover concrete in the joint core. Some penetration of crushing between the hoops into the core concrete occurred, which reduced the area of the column section available to carry axial load. In the later loading runs some plastic rotation continued to occur in the beams, but the predominant contribution to the deformation of the unit came from the shear distortions of the joint core. The appearance of the joint region at the end of loading runs $4,6,12$ and 14 is shown in Fig. 9. It is evident that repair of the joint core after damage of this extent and type would be extremely difficult.

Some pinching of the moment-deflection loops is evident in the later loading runs in Fig. 8. The reduced stiffness at the start of the pinched loops is due to displacements which occurred along open diagonal tension cracks in the joint core and also to some extent across open flexural cracks in the compression zone of the beams caused by tension in the previous loading run. Increase in stiffness occurred when these cracks tended to close, as the uneven faces bore together enabling shear and compression to be transferred along and across these cracks.

The maximum beam moment reached in the first inelastic loading run (run 3) was within $1 \%$ of the theoretical beam flexural strength, but in the first inelastic loading run in the reverse direction (run 4) the maximum beam moment reached was $10 \%$ less than the theoretical flexural strength. This low moment capacity, and subsequent lower peak values in the later loading runs, was due to the early shear failure of the joint core which meant that the beam could not again attain its flexural strength.

Fig. 10 shows the distribution of the measured joint hoop strains at the peaks of loading runs 1 to 10 . The inner joint hoops commenced yielding in loading run 3 when the maximum moment capacity was first reached in one direction. In the loading runs that followed the three inner joint hoops reached yield stress and the hoop strains continued to increase. The yielding of these hoops allowed large diagonal cracks to form in the joint core. As the joint core deformed under the reversals of shear force, the diagonal tension cracks opened and closed in alternating directions and grinding and sliding of concrete occurred along the surfaces of the cracks. The joint core hoops that did not reach yieldwere the topmost hoop (between the two layers of top beam bars) and the bottom most hoop (between the two layers of bottom beam bars). From this observation it can be concluded that the hoop reinforcement across the top and the bottom of the joint core was adequate and that any more transverse steel in the potential plastic hinge regions of the columns adjacent to the joint core would not have improved the performance of the joint core.

Fig. 11 shows the moment-strain curves measured for the outer layer of the top and bottom longitudinal steel. These strains were measured over a $102 \mathrm{~mm}$ gauge length commencing $29 \mathrm{~mm}$ from the column face. The moment plotted is that at the centre of the gauge length. Tensile strains are taken as positive. It is evident that after the initial yielding in tension the longitudinal steel had a permanent, and increasing, tensile elongation during the subsequent loading runs. That is, the inelastic strains resulting in flexural deformations were mainly due to tensile yielding and full depth flexural cracking at the critical sections was present during most of the inelastic loading runs. The flexural cracks in the compression zone tended to close at near peak moments, as may be observed in the curves of Fig. 10 where the slope of the curves increases near the peaks of compressive strain loading. This effect is more pronounced in the moment-strain curves for the bottom steel where the imposed tensile straining was not as great as for the top steel and hence the cracks closed more readily. The tendency for the steel strain to become compressive is reduced when the concrete commences to carry some compressive force. The absence of any significant visible crushing of the concrete in the plastic hinge regions of the beams in Fig. 9 is due to the moment being carried mainly by the steel forces across the full depth flexural cracks.

\section{CONCLUDING DISCUSSION:}

The interior reinforced concrete beam-column joint unit was designed so that plastic hinging occurred in the beams adjacent to the column faces during seismic type loading. The draft SANZ concrete design code requirements for vertical shear reinforcement in the joint core was met by the intermediate column bars present. However, the quantity of horizontal shear reinforcement in the joint core in the form of hoops was only $78 \%$ of that required by the draft SANZ code. The joint core hoops commenced to yield in the first loading run up to the flexural strength of the beams. With subsequent loading runs 


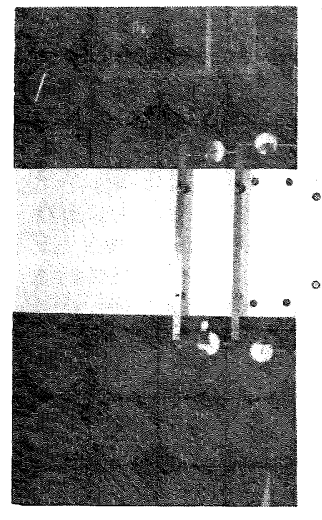

(a) End of Loading Run 4

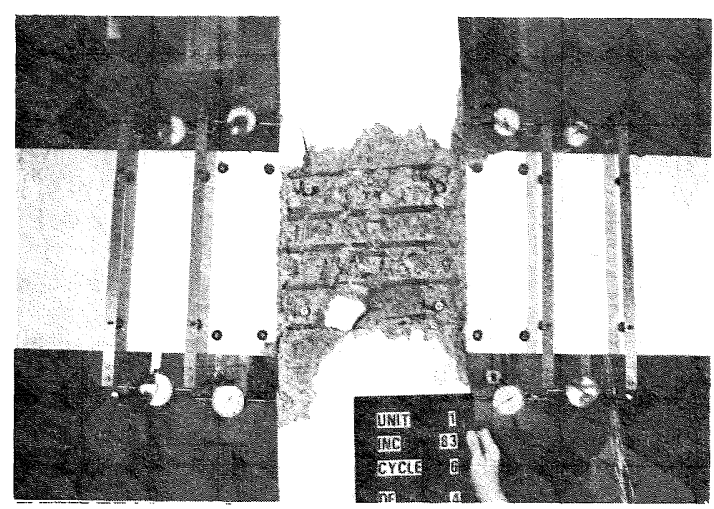

(c) End of Loading Run 12

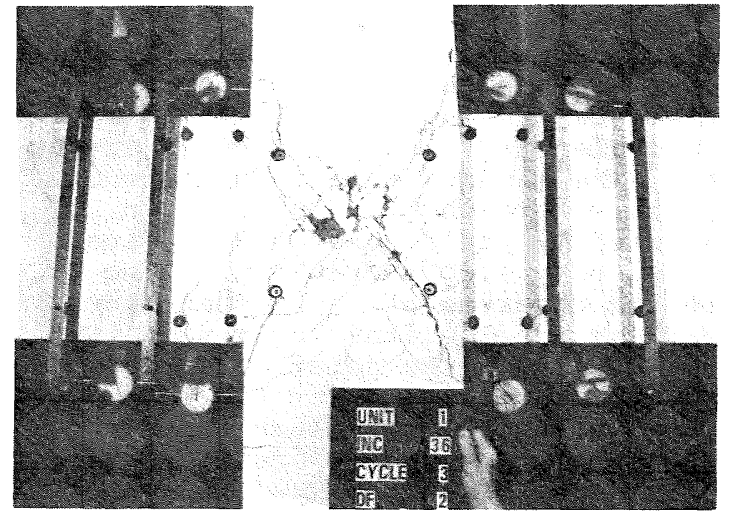

(b) End of Loading Run 6

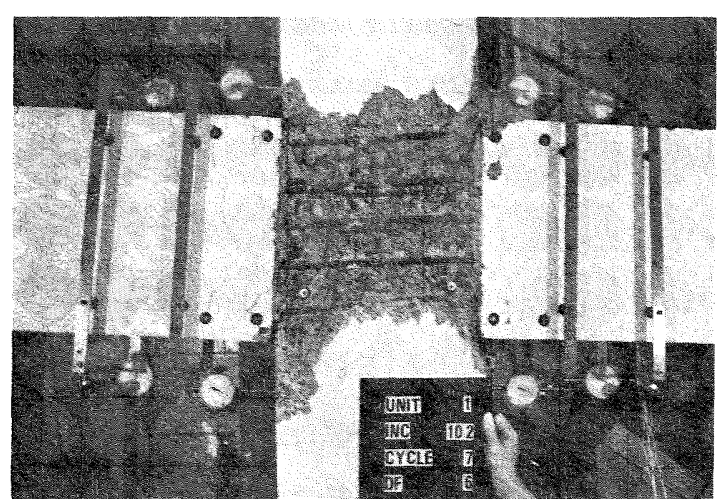

(d) End of Loading Run 14

Fig. 9 Appearance of Joint Region During Testing

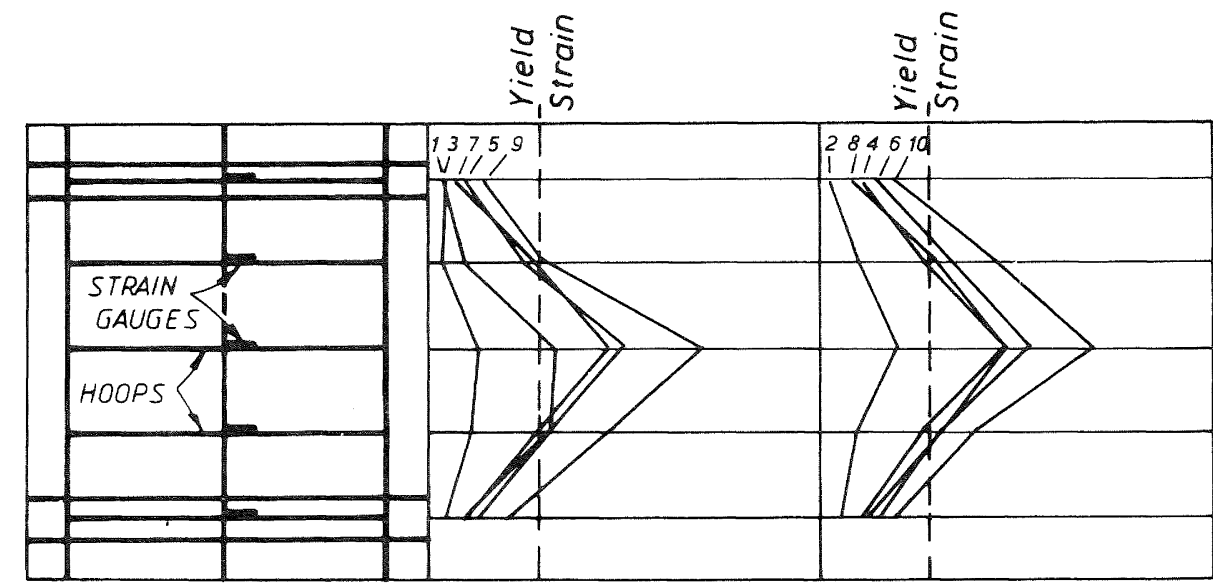

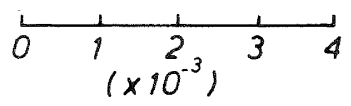

(a) Joint Reinforcement (b) Strains. odd Loading Runs

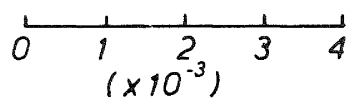

(c)sirains, Even Loading Runs

Fig. 10 Distribution of Measured Hoop Strains at Peak of Loading Runs 1 to 10 


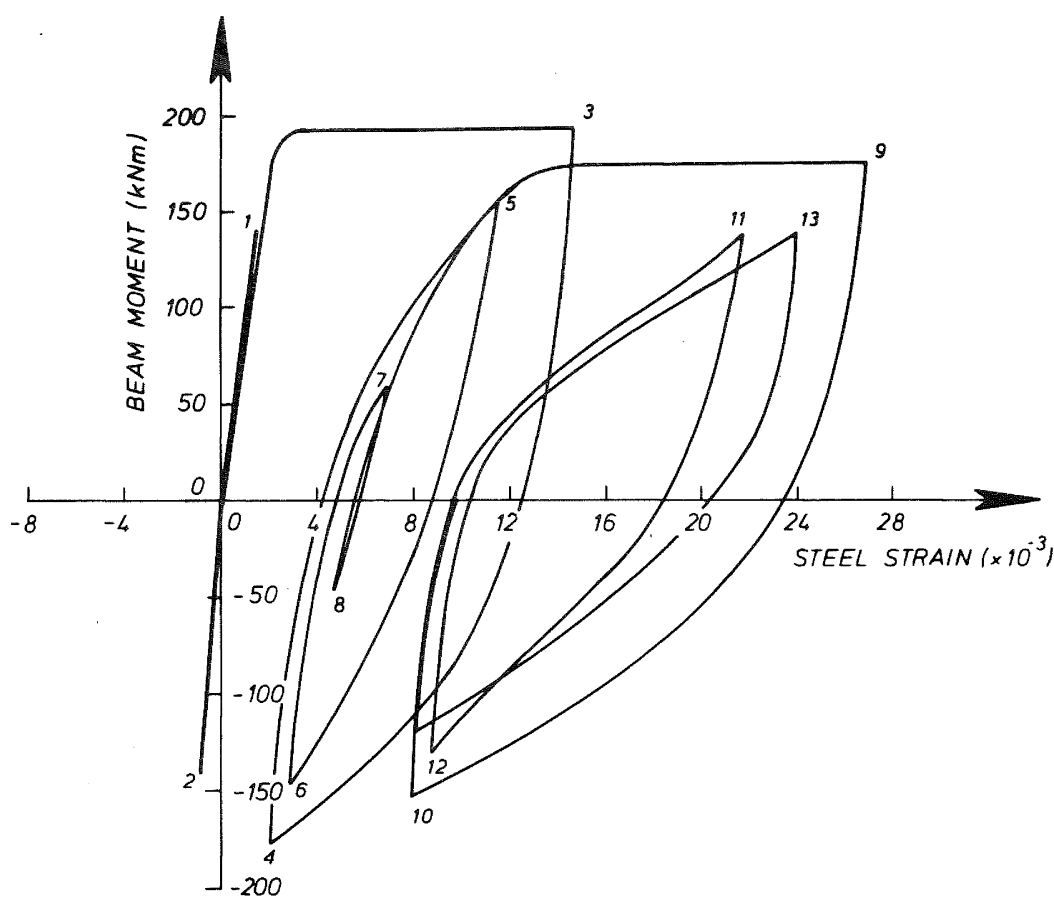

(a) Top Steel Outer Layer

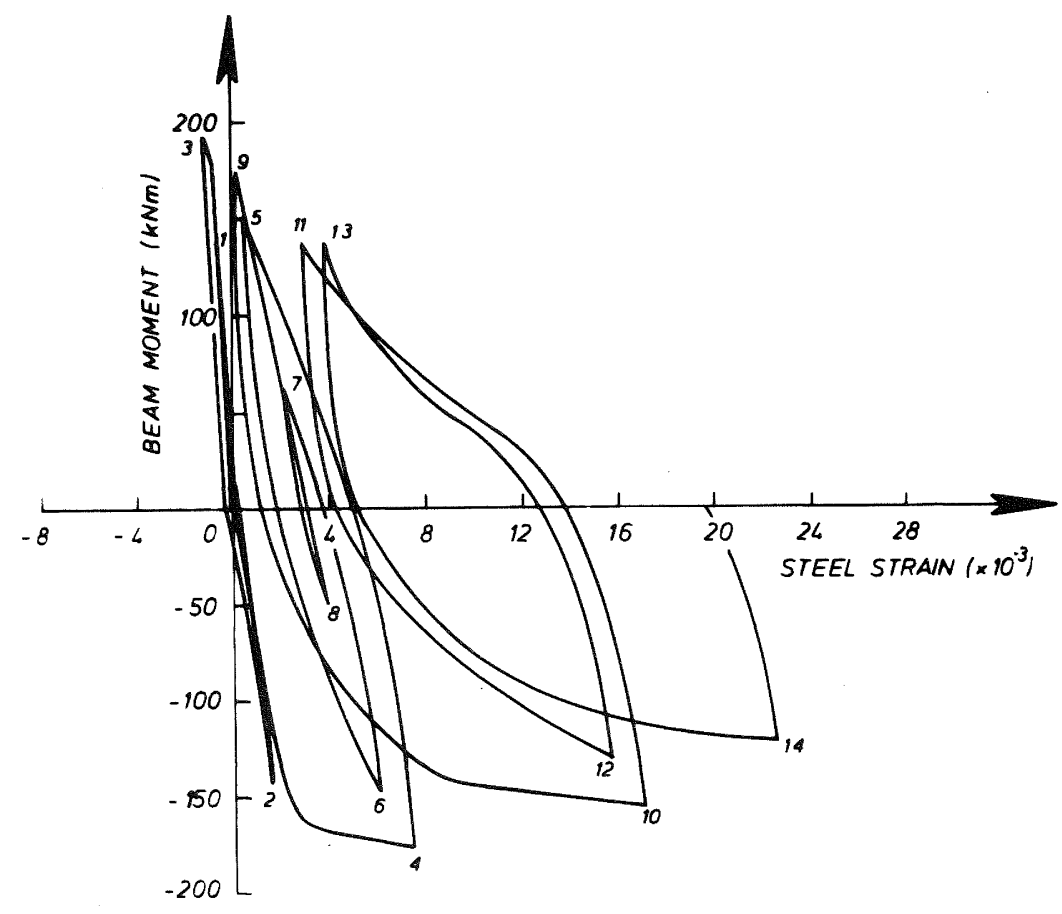

(b) Bottom Steel Outer Layer

Fig. 11 Measured Moment in Left Beam at $79 \mathrm{~mm}$ from Column Face Versus Average Strain in $102 \mathrm{~mm}$ Gauge Length in Left Beam Commencing $29 \mathrm{~mm}$ from Column Face 
ductile flexural yielding of the plastic hinges in the beams could not dominate the response of the unit since degradation of stiffness and strength of the unit occurred due to damage concentrating in the joint core. It is evident that the draft SANZ code is not over conservative in its approach to the design of interior beam-column joints of seismic resistant frames.

Shear failure of beam-column joint cores is undesirable since, apart from the non-ductile nature of the resulting deformations, structural collapse of the frame could result from the loss of load carrying capacity of the column due to the damaged joint core. In any case repairs would be difficult.

A comparison of the theoretical horizontal shear strength of the joint core calculated by various codes showed that the procedures of the ACI and SEAOC codes, and of ACI-ASCE Committee 352, gave smaller shear strengths (were more conservative) that the draft SANZ code for this test unit.

The use of longitudinal beam reinforcement with a diameter of $\frac{1}{25}$ th of the column depth was found to result in satisfactory behaviour in that no significant slip of the bars through the joint core of the test unit was observed.

\section{ACKNOWLEDGEMENTS:}

The tests were conducted by E.C. Stevenson during Master of Engineering studies under the supervision of R. Park and L. Gaerty. Thanks are due to the University of Canterbury for financial support.

\section{REFERENCES :}

1. "Draft New Zealand Standard Code of Practice for the Design of Concrete Structures", DZ3101:Part 1, Standards Association of New Zealand, Wellington, 1980.

2. ACI Committee 318, "Building Code Requirements for Reinforced Concrete (ACI 318-77)", American Concrete Institute, Detroit, 1977.

3. "Recommended Lateral Force Requirements and Commentary", Seismology Committee, Structural Engineers Association of California, San Francisco, 1975.

4. ACI-ASCE Committee 352, "Recommendations for Design of Beam-Column Joints in Monolithic Reinforced Concrete Structures", Journal of American Concrete Institute, Proc. Vol. 73, No. 7, July 1976, pp. 375-393.

5. Park, R. and Paulay, T., "Reinforced Concrete Structures", John Wiley and Sons, New York, 1975, 769pp.

6. Paulay, T., Park, R. and Priestley, M.J.N., "Reinforced Concrete BeamColumn Joints Under Seismic Actions", Journal of American Concrete Institute, Proc. Vol. 75, No. 11, November 1978, pp. 585-593.

NOTATION:

a

$\mathrm{A}_{\mathrm{g}}$

$\mathrm{A}_{\mathrm{S}}$

$A_{S}^{\prime}$

$\mathrm{b}$

c

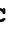

C

$\mathrm{C}_{4}$

d

d

$\mathrm{h}_{\mathrm{b}}$

$\mathrm{h}_{\mathrm{C}}$

$\mathrm{P}$

$\mathrm{T}_{1}$

$\mathrm{T}_{3}$

3 = tensile force in reinforcement in layers 1,2 and 3 , respectively

$\mathrm{V}_{\mathrm{col}}=$ shear force in column

$\mathrm{v}_{j h}=\underset{\substack{\text { horizontal shear force in joint } \\ \text { core }}}{v}$

$\rho \quad=A_{S} / b d$

$\rho^{\prime} \quad=A_{S}^{\prime} / \mathrm{bd}$

$\phi \quad=$ strength reduction factor 